\title{
A model of the antecedents of multiple channel usage
}

\author{
Filipe Coelho $^{\mathrm{a}, *}$, Chris Easingwood $^{\mathrm{b}}$ \\ ${ }^{\text {a } F a c u l d a d e ~ d e ~ E c o n o m i a ~ d a ~ U n i v e r s i d a d e ~ d e ~ C o i m b r a, ~ A v . ~ D i a s ~ d a ~ S i l v a, ~ 165, ~ 3004-512 ~ C o i m b r a, ~ P o r t u g a l ~}$ \\ ${ }^{\mathrm{b}}$ Manchester Business School, Manchester, M15 6PB, England
}

\begin{abstract}
The number of companies using multiple channels in the distribution of each of their products is increasing steadily. Despite this popularity, the drivers of these channel strategies remain virtually unknown. This work attempts to deal with this problem by developing a model regarding the circumstances under which companies adopt multiple channel strategies. Data collected from companies in the UK financial services industry provide significant empirical support to the model. The results indicate that product sophistication, market target sophistication, channel conflict, market maturity, scope economies, and competitive strength, are important considerations in the multi-channel move.
\end{abstract}

(C) 2007 Elsevier Ltd. All rights reserved.

Keywords: Multiple channels; Distribution; Financial services

\section{Introduction}

A multiple channel strategy is employed when a firm makes a product available to the market through two or more channels of distribution (Gassenheimer et al., 2006; Webb and Hogan, 2002), usually with the purpose of extending a firm's market coverage (Lassar and Kerr, 1996). The number of companies using a multiple channel strategy for the distribution of their products is increasing steadily, thus becoming the most popular channel design (Gassenheimer et al., 2006; Moriarty and Moran, 1990; Sa Vinhas and Anderson, 2005). In this context, building a coherent distribution structure is both a major challenge and a primary concern for most companies.

Despite the popularity of multiple channel strategies, their design has been virtually unexplored (Bradach and Eccles, 1989; Cespedes and Corey, 1990; Dutta et al., 1995; Easingwood and Storey, 1996; Frazier, 1999; Gassenheimer et al., 2006; Rangan et al., 1993; Sa Vinhas and Anderson, 2005). This is of particular concern because, according to the reasoning of Stern et al. (1996, p. 31), "a prerequisite to

\footnotetext{
${ }^{*}$ Corresponding author. Tel.: + 351239790574.

E-mail addresses: fcoelho@fe.uc.pt (F. Coelho), ceasingwood@man.mbs.ac.uk (C. Easingwood).
}

the effective management of marketing channels is a knowledge of the reasons channels exist, the functions they perform, and the factors that account for the way they are structured". Consequently, multiple channels can only be properly managed if there is an understanding of the reasons why such distribution structures emerge. This knowledge enables managers to more systematically select specific channels, and coordinate efforts amongst channels to maximise the effectiveness of distribution arrangements. Not surprisingly, the general press is plagued with news of companies that have grossly failed in dealing with these distribution structures.

The difficulties created by this theoretical vacuum have certainly increased with the recent expansion in the number of available channels. Consequently, shedding light on the drivers of multiple channel strategies constitutes an extremely important and timely research avenue. The purpose of this work is thus to enhance our understanding of the antecedents of multiple channel designs. In particular, this work attempts to widen the discussion by examining the value of some alternative theoretical perspectives, namely the literature on marketing channels, the resource-based view and on the environment-organization fit. Furthermore, we develop a measure of the intensity to which a firm uses multiple channels. 


\section{A model of the antecedents of multiple channel usage}

Despite the general acknowledgement of the widespread utilization of multiple channels, very few studies have empirically researched their design. These include the works of Dutta et al. (1995), which used a transaction cost framework, Coelho and Easingwood (2005), which used an environmental uncertainty approach, and Sa Vinhas and Anderson (2005), which focused on the sources of channel conflict. Other papers also investigate the issue of multiple channels. However, they do so from the perspective of managing these channel structures, and not their design (e.g., Gassenheimer et al., 2006). In this work we depart from previous research by considering mostly new variables drawn from the marketing channels theory, the resource-based view, and the environment-organization fit literature. We use these theories to develop the model in Fig. 1, which informs about the antecedents of the design of multiple channel structures.

Channel service outputs: In the marketing literature, channels have been defined "as sets of inter-dependent organizations involved in the process of making a product or service available for consumption or use" (Stern et al., 1996 , p. 1). These channels create a set of benefits to consumers by delivering a number of logistical and informational service outputs. Therefore, channels will survive and develop to the extent to which they are able to meet the needs of a significant number of consumers. Thus, multi-channel designs must consider the characteristics of the target market and their needs for service outputs.

In this context, we propose product sophistication, market target sophistication, and channel conflict as three important factors influencing the development of multichannel structures. Product line sophistication increases the level of consumer involvement (Schiffman and Kanuk, 1991) and, therefore, affects their desired service levels. Research also indicates that it affects the channel activities to be performed and the need for co-ordination and control that firms should exert over distribution channels (Majumdar and Ramaswamy, 1995). Sophisticated consumers have more complex service needs, require more service, and adopt innovations earlier than others (Rogers, 1995), and

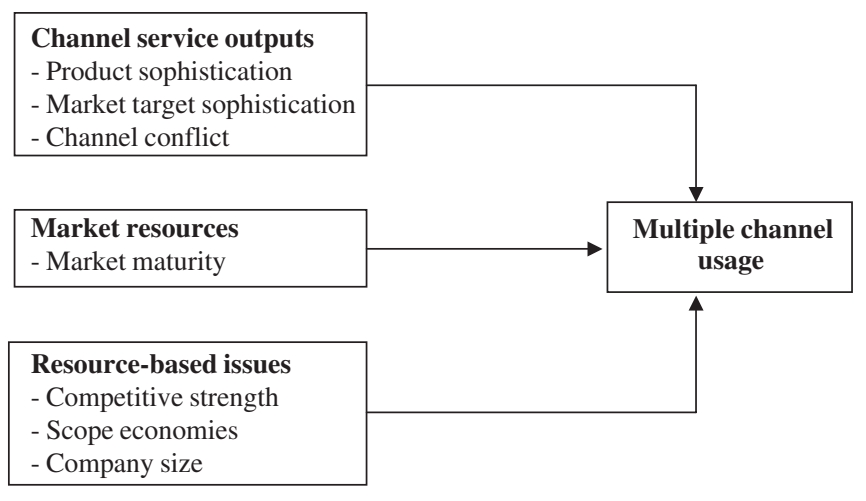

Fig. 1. A model of the antecedents of multiple channel usage. this should also influence channel design. Finally, we consider channel conflict, which has a strong influence on the degree of co-operation amongst channel members, thus affecting the service outputs delivered to consumers.

The organization-environment fit: The impact of the environment on organizational structures and inter-organizational arrangements has long been acknowledged (see, for example, Aldrich, 1979; Pfeffer and Salancik, 1978). This idea that the environment should affect organizational choices arises from the observation that "the maintenance of organizations depends upon some degree of exchange with outside partners" (Child, 1972, p. 3). Pfeffer and Salancik (1978, p. 2) went further, stating that the key for an organization to survive "is the ability to acquire and maintain resources". Since organizations require a steady flow of resources to work properly, they must manage their dependency, and this implies fitting strategies to the resources available in the environment. We thus considered "market maturity", reflecting the level of resources that are available to a company in its environment.

Resource-based issues: According to the resource-based view, firms consist of bundles of resources and capabilities that are "heterogeneously distributed across competing firms ... [and] are imperfectly mobile" (Barney, 1991, p. 97). Chandler (1992, p. 86) notes that it is "the specific nature of the firm's facilities and skills [that] becomes the most significant factor in determining what will be done" by a firm. Consequently, a firm's resources and capabilities act as a source of advantages and constraints, dictating successful and unsuccessful paths, thus influencing the feasibility and willingness of venturing into multi-channel distribution. Accordingly, we consider a firm's competitive strength, which Burke (1984) found, determines to a certain degree, the strategic thrust of a business unit, and thus should have an impact on a firm's investment in multiple channels. We also propose scope economies and company size as two complementary strong indicators of a firm's propensity to use multiple channels, which is a resourcedemanding strategy (Dutta et al., 1995). These two variables capture a firm's ability to afford particular channel structures and also to recover the costs of particular channel structures should they not prove successful (see Dutta et al., 1995).

\subsection{Channel service outputs}

Product sophistication: A sophisticated product, defined as the extent to which the product is elaborate and refined, tends to be characterized, for example, by a strong degree of technical complexity and long-term commitment (see, for example, Anderson et al., 1987). Sophisticated products generally raise the level of consumer involvement. When consumers are very concerned with a specific purchase, they tend to seek out more information as well as personal sources of information before making their purchase decisions (Schiffman and Kanuk, 1991), in order to ensure that the product fits their needs and that they do not lose 
important benefits. Consequently, communication between consumer and distribution channel is likely to be intense and frequent (Bucklin et al., 1996).

Therefore, the complexity of sophisticated products should restrict the number of channels capable of appropriately delivering the service outputs required by consumers. Furthermore, reliance on a lower number of channels facilitates the coordination and close control over the way distribution functions are performed (Bucklin et al., 1996; Majumdar and Ramaswamy, 1994, 1995). It has been stated, for example, that “ $\ldots$ when close coordination is needed, manufacturers are likely to limit distribution to reduce potential difficulties in channel operations and foster a supportive atmosphere in their exchange relationships" (Frazier and Lassar, 1996, p. 47). In fact, the usage of multiple channels is likely to be seen by channel members as a lack of commitment by the supplier, decreasing trust and the performance of the channel system (Brandenburger and Nalebuff, 1996; Hibbard et al., 2001; Jap, 2001). Hence, product sophistication should be negatively related with the use of multiple channels.

However, Sa Vinhas and Anderson (2005) argue that channel types collide when they sell standardized products. This is the result of the lack of opportunities for competing channels to differentiate in ways other than price and service. Based on this argument, we predict a quadratic relationship between product sophistication and multichannel usage. At low levels of sophistication, products are sold through fewer channels, to avoid strong inter-channel conflict. As product sophistication increases, so does the room for competitors to differentiate on other dimensions, thus enabling the utilization of additional channels. At very high levels of sophistication, however, ensuring the delivery of the service outputs required by consumers, should become paramount, thereby inducing a reduction of multichannel usage.

H1. The relationship between product sophistication and multi-channel usage is described by an inverted $U$ function.

Market target sophistication: Consistent with previous research (e.g. Degeratu et al., 2000; Gatignon and Robertson, 1991), we define market target sophistication as the extent to which a firm's customer target has a higher income and education. Several studies indicate that upscale consumers tend to be more demanding and innovative. They are more likely to adopt new consumer electronics products (Im et al., 2003) and to prefer technologyintensive financial organizations (Filloto et al., 1997).

Following the argument of Wheelwright and Clark (1992, p. 2), increased sophistication implies that customers are more sensitive to differences in offers, being attracted to solutions that best fit their particular needs. As they are demanding products from an increasing variety of channels (Alba et al., 1997), and this will be particularly true for upscale consumers, companies have to address these needs by using multiple channels. This strategy enables a company to offer the type of service the customer requires at any moment. Failure to deliver in this respect should originate alienation within a firm's customers. We thus predict the following:

H2. Market target sophistication will be positively associated with multiple channel usage.

Channel conflict: The use of multiple channels implies that "more marketing units compete for customers and revenues" (Moriarty and Moran, 1990, p. 147), a situation that is very likely to create conflict among channels. Multiple channels also increase the likelihood that a customer will use different channels on different occasions, which creates the problem of "who owns the customer". This is a particular concern for the initial channel because latecomer channels might free ride on the former's efforts to win the customer in the first instance (Stern et al., 1996, p. 311). Conflicts also arise because different channels may fight for the limited resources of the supplier. Each channel is likely to ask, for example, for priority in product development efforts and/or in promotional assistance.

The likely consequences of conflict include lower channel motivation, an increased lack of co-operation among channel members, deterioration of service levels, more intermediary bias towards competitors' products, and degradation of communication flows. Ultimately, conflict results in customer dissatisfaction, intermediary attrition, and in a loss of market share. Levi's started to sell its jeans directly through the Internet a few years ago but had to abandon its use of this channel because of strong objections by its other retail channels (The Economist, 2000, p. 16). Hence, the development of a multi-channel structure can pose serious channel management issues, and these should be addressed at the channel design stage (Rangan et al., 1992; Stern et al., 1993). In this context, as compatibility among channels increases, companies can enjoy the benefits provided by a large number of channels, with less negative side effects.

However, it can also be argued that organizations may wish to introduce a certain level of manageable competition into their distribution, thereby keeping channels on their toes and increasing the performance of the entire system. This consubstantiates the idea that the proper management of co-operation and the presence of moderate levels of competition in the channel system may originate positive outcomes (Bengtsson and Kock, 2000; Brandenburger and Nalebuff, 1996; Gassenheimer et al., 2006). Therefore, we propose that at high levels of channel conflict, a negative relationship will prevail because firms will want to avoid its likely destructive effects. At low levels of conflict, a positive relationship will emerge, to take advantage of the benefits associated with moderate channel conflict.

H3. The relationship between channel conflict and multichannel usage is described by an inverted $U$ function. 


\subsection{The organization and its environment}

Market maturity: Large demand, smaller growth prospects and higher levels of competitive intensity are attributes of mature markets (Achrol et al., 1983; Aldrich, 1979; Dwyer and Welsh, 1985). We predict that companies are more likely to develop multiple channels in mature markets, and the reasons are as follows. A larger number of channels often require firms to make substantial additional investments. Banks, for example, have been investing millions in call centres, ATMs, digital TV and Internet. Firms also have to recruit more personnel in order to control and extend support programmes to the new channels and to cope with the additional logistical workload. Consequently, the utilization of multiple channels is likely to increase a firm's investment and operational costs in absolute terms. In this context, a market must be large enough, i.e. it must comprise the demand, for example, in order to provide organizations with sufficient resources to recover the larger costs and investments that are frequently implied by multiple channels. Not surprisingly, the rapid growth in the computer market by the beginning of the 1980s was an important reason for leading manufacturers to add more channels to their distribution structure (Cespedes, 1988). Consequently, mature markets make the utilization of multiple channels feasible, whereas the demand available in new markets makes it more difficult to justify a multi-channel strategy.

In addition, multiple channels maximise market presence, which in more mature markets is the major determinant of sales (Farris et al., 1989). Simultaneously, by diversifying one's sources of business, the utilization of multiple channels also probably serves as a buffer, protecting the company against a more aggressive environment. In summary, a positive relationship is predicted between market maturity and number of utilized channels.

H4. Market maturity will be positively associated with multiple channel usage.

\subsection{Resource-based issues}

Competitive strength: According to Burke (1984, p. 347), competitiveness is an indication of a firm's position and ability to compete and it reflects different ways under which companies move around in their environment. In every market there are companies with different strategic behaviours, some being characterized by reactive behaviour, and others by more proactive conduct. The latter will be those companies that more closely monitor the environment, that first tend to anticipate and react to environmental changes. They will be the first to identify new trends in consumer needs and to use technological developments to serve them in better ways. Hamel and Prahalad (1995, pp. 37-38) noted that such companies "fundamentally change the game in ways that disadvantage incumbents - devising novel approaches to market entry, advantage building and competitive warfare ... the goal is not competitive imitation but competitive innovation". Hence, the more skilful players attempt to shape the rules of competition to their own advantage.

Multiple channel strategies are becoming increasingly popular distribution arrangements, as a result of several developments, which include the appearance of more sophisticated customers demanding more tailor-made offers and more specific channels, and also of technological developments, which have increased the range of channels available for companies to use. In this context, it can be expected that the more competitive companies will be the first to develop multiple channels. Following the resourcebased view (Barney, 1991), these companies, which derive their advantages from resources and skills not easily imitable, are more practised at developing and maintaining resources and skills that fit the environment, and at selecting strategies and positions that exploit them. They are the ones more likely to think ahead and to develop first mover advantages, namely in developing new distribution channels. We therefore predict:

H5. A firm's competitive strength will be positively associated with multiple channel usage.

Scope economies: Scope economies can be measured by the number of product lines marketed by a firm, thus expressing the degree to which it can spread costs and investments through different product lines. As discussed above, the multiple channel strategy is resource demanding, and hence, managing and implementing multiple channels seems to require the capacity to absorb additional investments and costs.

Companies marketing a large product range will have increased possibilities to specialize their human and technological assets in the context of multiple distribution structures. A large and related number of products also creates shared customers within a firm's business units and an overlap of resources, which facilitates improved coordination and ability to carry such distribution channels. Therefore, the larger a firm's scope economies, the higher its ability and willingness to invest in more channels. Companies with small scope economies are better off by creating simpler and more economical structures, comprising fewer different types of channels. In summary, significant scope economies can constitute an important entry barrier and justify a firm incurring the high costs of more complex distribution structures (Cespedes, 1988; Majumdar and Ramaswamy, 1995). As observed by Dutta et al. (1995), low scope economies can prevent a company from investing in dual (both direct and indirect) channels. We thus predict:

H6. Scope economies will be positively associated with multiple channel usage.

Company size: Company size can be considered as a complementary measure for a firm's resources, thus implying that a large firm will be in a better position to 
develop multiple channel strategies. In addition, larger companies also tend to have a wider market experience, which enables them to manage more complex distribution structures (Sa Vinhas and Anderson, 2005). We thus predict the following:

H7. Company size will be positively associated with multiple channel usage.

\section{Methodology}

\subsection{Sample and data collection}

The setting for the study is the financial services industry, as multiple channels constitute a very common strategy in this sector (Easingwood and Storey, 1996). Based on existing electronic databases, which are not organized on a product basis, a convenience sample of one hundred and sixty (160) companies of varying dimension and channel strategies were selected, in order to ensure sufficient variability of organizational characteristics. The information was collected from key informants in sixty-two (62) companies (a response rate of $39 \%$ ) through a personally administered pre-tested questionnaire. This research strategy also enabled the researchers to collect qualitative data during interviews. Typically, the respondents held sales and marketing executive responsibilities. In terms of size, 10 companies had less than 100 employees, 18 had between 100 and 1000 employees, 23 had between 1000 and 5000 employees, and the remaining 11 had more than 5000 employees. The average company had about 5100 employees.

The unit of analysis in this research is the channel mix for a particular product, and this conforms to the study of Sa Vinhas and Anderson (2005). Multi-product companies tend to use different channel mixes for different types of products (Degeratu et al., 2000; Zettelmeyer, 2000), the reason being that different channels do not convey equally well the attributes of different products.

Consequently, the study was restricted to four different financial products: motor insurance (13), personal pensions (16), mortgages (17), and unit trusts (16). Limiting the study to a small number of products was thought to be important in order to ensure some sample variability in terms of channel choice and, at the same time, to avoid too much variability, which could cause meaningless results. The four products were chosen based on the information obtained from the general press and also from six preliminary interviews with managers in financial services. These products are frequently associated with different channel mixes. Personal pensions are at one extreme of the distribution spectrum, with a heavy reliance on face-to-face channels. This is the result of this product's complexity, which requires an extensive service. At the other extreme is motor insurance, which is like a commodity product, and that has made major inroads into direct marketing. In between we have mortgages and unit trusts.

\subsection{Measures}

The multi-item measures used in this study, which were summated and averaged to obtain a measure for each construct, are presented in the Appendix. They were all measured on a 7-point scale, except scope economies and firm size. Product sophistication, measured on a bipolar scale, has a coefficient alpha of 0.86 , and was based on the works of Anderson et al. (1987) and Bello and Gilliland (1997) - items specific to financial services were considered. The average inter-item correlation is 0.51 . For measuring market target sophistication we used a scale anchored 'strongly disagree/strongly agree' with two items developed by the authors, but that are grounded on previous research (e.g., Degeratu et al., 2000; Gatignon and Robertson, 1991). The correlation between the items is 0.89 .

Channel conflict, which was also measured on a scale anchored 'strongly disagree/strongly agree', was developed by the authors, based upon the theoretical framework previously described. Its inter-item correlation is 0.76 . A firm's competitiveness was measured with a bipolar scale based on the work of Burke (1984). This has a coefficient alpha of 0.69 and an average inter-item correlation of 0.42 . As to market maturity, which has an inter-item correlation of 0.41 , this was also measured with a bipolar scale, finding its roots in the 'market attractiveness' or 'output sector variability' concepts of Burke (1984) and Dwyer and Welsh (1985), respectively. For scope economies, and following the work of Dutta et al. (1995), respondents indicated the number of product lines marketed by their company. Finally, for measuring company size we used the number of employees, which was subsequently logarithmized to reduce skewness.

A note of caution is warranted with the internal consistency of market maturity. The sample covers four products. Thus, it is possible that different products in the same stage may face different growth prospects, thus reducing the correlation between the items. Consequently, the market maturity measure should be considered an index-based measure, rather than a traditional measurement scale. In the latter, all constituent items measure the same construct and should therefore be correlated, whereas in an index-based measure, items are supposed to measure different constructs, explaining why its items do not necessarily have to be that correlated. Thus, market maturity should probably be considered a formative rather then a reflective scale (see Diamantopoulos and Winklhofer, 2001; Hair et al., 2002). Another implication is that the coefficient alpha is not appropriate to assess the psychometric properties of these scales (see, for example, Howell, 1987; Klein et al., 1990).

Factor analysis revealed that each of the previous multiitem measures is unidimensional. Following the suggestion of Netemeyer et al. (2001) that inter-item correlations above 0.30 are very good, we conclude about the acceptable reliability for the multi-item measures. Evidence of discriminant validity is provided by a correlation 
coefficient between a scale and any other scale that is lower than its coefficient alpha (Andaleeb, 1995; Gaski and Nevin, 1985). All refined scales in the study to which the coefficient alpha is applicable (scales with three or more items) meet this requirement. In addition, the correlation coefficients have no excessively large magnitudes, which is evidence that there is no major overlap among the independent variables in the study. The Appendix presents some basic statistics and the Pearson correlation coefficients.

In order to assess a company's channel strategy a channel typology had to be established. A fundamental distinction is between direct and indirect channels, which imply distinct resource needs, management competencies, controls, and flexibility. However, and following Easingwood and Coelho (2003, pp. 33-34), within direct channels we further distinguished between traditional and direct marketing channels. This strategy also addresses the explosion in direct marketing (Cravens, 2000), and its growing use by financial services organizations.

Traditional direct channels include the branches and direct salesforces of banks, building societies and pension companies. These fully-controlled channels allow companies to enjoy the benefits associated with integration, and deliver high levels of personal contact to consumers, but are not very flexible investments. Separating branch networks from the direct salesforce would entail an artificial division. For example, banks have a regulated salesforce to sell products such as pensions that is frequently based in the branch, but these salespeople may also visit customers at their home and even at their place of work. Therefore, it is not feasible to separate branch from non-branch activities. The critical elements are that both are fully controlled and involve face-to-face contact between a representative of the financial company and the customer.

Direct marketing channels include direct mail, direct response advertizing, the telephone and the Internet. They are also fully controlled by the company, but require less capital investments than the traditional brick and mortar channel, thus generating a lower overhead structure. Another specificity is that they can only provide limited assistance to buyers. Distinguishing these different channels was rejected based on the feedback provided by the interviews. For example, a direct marketing company may obtain its sales by generating leads through direct response advertizing, which may precipitate a purchase via the telephone supported by mail delivery of the insurance certificate. These channels are integrated and therefore it would be artificial to try to separate them. In addition, considering direct response advertizing separately from the telephone or direct mail could lead to an artificial inflation in the number of used channels for some companies.

Given the notorious absence of channel typologies (Frazier, 1999), this research considered that although crude, the three channel types' classification (traditional direct, direct marketing, and intermediaries) would enable the accomplishment of the study's objectives. Although a more detailed definition of channels can be appropriate in certain circumstances, channels are frequently inter-woven, which is the reason why very fine classifications can also be somewhat artificial. The distinguishing features in the present classification are resources, control and personal contact, which are critical elements in a channels context. In addition, the three types of channels also involve quite different management capabilities.

Hence, the channel strategy used by each company for the distribution of one of the considered products was measured by assessing the percentage of sales conducted over those three types of channels. This data can be used to assess a company's channel strategy by simply counting the number of utilized channels. However, this procedure is inappropriate, as a company obtaining sales from two distinct channels in the percentages of $98 \%$ and $2 \%$ would receive the same classification as a two-channel company with product sales in the proportions of $60 \%$ and $40 \%$. The latter has a balanced multi-channel strategy, whereas the former is basically using a single channel strategy.

Consequently, this research developed a continuous measure reflecting the intensity with which a company is using multiple channels. This measure was built by multiplying the sales percentages obtained through the utilized channels, this product being subsequently divided by 1000 and logarithmized in order to reduce deviations from normality. This multiplicative function ensures that the measure of multiple channel intensity is positively related with number of channels and with the balance of sales over the three different channels. For example, a company obtaining its sales from three channels in the proportions of $40 \%, 35 \%$ and $25 \%$ would have a multichannel intensity of $\log (40 \times 35 \times 25 / 1000)=3.55$. The maximum multi-channel intensity occurs when a company balances its sales across the channels, i.e. it obtains $33.33 \%$ from each of the three channels. However, one deviation from this procedure had to be introduced, and is as follows. Under the above approach, a company obtaining its sales from two channels in the proportions of $99 \%$ and $1 \%$ would obtain a multi-channel intensity of -2.31 , which is inferior to the multi-channel intensity of the single channel company. Consequently, whenever a channel accounted for $1 \%$ of the sales for a particular company it was considered to generate instead $1.5 \%$ points, yielding a multi-channel intensity of -1.91 , between that of a single channel company and that of a company obtaining its sales in the proportions of $98 \%$ and $2 \%$.

\subsection{Estimation results}

Before the quadratic terms were formed all variables in the study were mean-centred, in order to reduce the resulting multi-collinearity. Given the relatively small sample size, we used step-down hierarchical regression for hypotheses testing. First, we ran the complete model. Subsequently, we removed the least non-significant variable, company size. After this stage, all remaining 
Table 1

Estimation results

\begin{tabular}{lrl}
\hline Variable & \multicolumn{1}{l}{$B$} & $\mathrm{SE}$ \\
\hline Constant & 0.974 & $0.335^{*}$ \\
Product sophistication & -0.059 & 0.214 \\
Product sophistication $^{2}$ & -0.321 & $0.125^{*}$ \\
Market target sophistication $^{\text {Channel conflict }}$ & 0.271 & $0.160^{* *}$ \\
Channel conflict $^{2}$ & 0.081 & 0.123 \\
Market maturity $_{\text {Competitive strength }}$ & -0.161 & $0.074^{* *}$ \\
Scope economies & 0.316 & $0.172^{* *}$ \\
Adjusted $R^{2} 42.5 \%$ & 0.494 & $0.193^{*}$ \\
$F$ value 6.645 (sign. $=0.000)$ & 0.509 & $0.141^{*}$ \\
\hline
\end{tabular}

Note: Tests of hypotheses are one-tail tests.

${ }^{*} p \leqslant 0.01$.

$* * p \leqslant 0.05$.

variables had a significant effect, and the process of model estimation stopped. We did not remove from the equation the non-significant first order terms associated with the statistically significant quadratic terms because they must be included in the equation for a more precise identification of the first and second order effects (Aiken and West, 1991).

Estimation results are reported in Table 1. The model developed has an $F$ value of 6.645 , which is significant at the 0.00 level. Also relevant is the adjusted $R^{2}$ of $42.5 \%$. We thus conclude that the variables in the equation have a significant discriminatory power over the company's channel choices. In addition, the largest VIF (variance inflation factor) is 1.94, indicating no sign of multi-collinearity, and the assumption of homoscedasticity, investigated through the White test, is accepted $(p>0.05)$. The results associated with hypotheses testing are now described.

The coefficient for the linear term of product sophistication is non-significant, whereas its quadratic term has a negative sign that is highly statistically significant. Hence, and as predicted, the relationship between these two variables seems to be solely described by an inverted $U$ function, that is, a downward symmetric curvilinear relationship, supporting $\mathrm{H} 1$. $\mathrm{H} 2$, which predicted a positive relationship between market target sophistication and multiple channel usage, is also supported.

$\mathrm{H} 3$ also predicted that an inverted $U$ function described the relationship between channel conflict and multiple channel usage. The coefficient for the first order term is non-significant and the quadratic term has a significant negative sign. These results indicate that the relationship between number of channels and channel conflict is described by a downward symmetric curvilinear relationship. Consequently, the relationship predicted in $\mathrm{H} 3$ receives full support.

With regard to market maturity, $\mathrm{H} 4$ posited that multiple channels are more likely to be found in mature markets. The coefficient for market maturity is positive and significant, and therefore support is found for H4. H5 predicted competitive strength to be positively related to multi-channel usage. The estimated coefficient supports this prediction, as it is positive and highly significant.

Scope economies also has a positive coefficient that is very significant. Therefore, the higher a company's scope economies, the higher the likelihood that it will use multiple channels, a result that supports H6. Finally, we did not find any association between company size and multi-channel usage, thus leading to the rejection of $\mathrm{H7}$. We now discuss these findings.

\section{Discussion and implications}

Little is known in a rigorous, systematic way about multi-channel structures. This is a problem of severe magnitude, given the popularity and implications of such strategies. This work has attempted to deal with this problem by developing and testing a model comprising a set of propositions regarding the circumstances under which companies develop multiple channels. The study's results, which support most of the hypothesized relationships, clearly suggest that companies with incoherent multichannel strategies (Moriarty and Moran, 1990) may not be that frequent, at least in the financial services industry. Companies seem to have been making multiple channel decisions on the basis of the trade-offs between several drivers of channel structure.

The relationship between multi-channel intensity and product sophistication is somewhat complex. At very high levels of sophistication, there is a negative relationship between sophistication and multi-channel usage. As sophistication increases, more channel collaboration is required, which is more difficult to ensure in the presence of intra-brand competition (Frazier, 1999; Frazier and Lassar, 1996). Additionally, these products are so difficult to sell that the number of channels through which a company can effectively sell them while still meeting consumers' needs is low. As one key informant in a pensions company stated, "There is not much channel strategy for pensions because of the complexity of the product that you are trying to sell, otherwise pensions over the telephone would have already taken off'.

At low sophistication levels, the relationship with multiple channel utilization is positive. For unsophisticated products, companies find it more desirable to concentrate their distribution efforts. This avoids collision between channels, given the difficulty of differentiating the offerings. Additionally, concentration of efforts in developing, serving and supporting a sole channel, promotes a certain positioning and even shield against competition. As was stated by one manager in a single channel motor insurance company, "Very niche products. [We] just make money, it is embarrassing, by controlling costs, controlling price and owning an area that we are very good at, very competent", a view that was reported by several other key informants. Furthermore, it is possible that when products are very simple, they become like commodity products, thus forcing firms to concentrate on the cheapest channel system for that product. 
Market target sophistication has a positive effect on the utilization of multiple channels. Sophisticated consumers are more demanding, and possibly require a wider variety of channels to contact their suppliers at any time and place. Thus, companies dealing with this type of consumers should respond to this by using multiple channels.

Support was also found for the effects of channel conflict on the number of channels. Conflicts arise because channels are social and economic entities, so that any adjustments to the implementation strategies can differentially affect channels leading to perceived conflict amongst those affected by such decisions. Consequently, firms frequently may have to implement a compromise solution to the detriment of more economical ones.

However, conflict only seems to preclude companies from using multiple channels at very high levels. At low to moderate levels, conflict seems to be tolerated and does not restrict the number of channels. Competition in the channel system can produce negative outcomes for intermediaries and consumers (Bengtsson and Kock, 2000; Dozoretz and Matanovich, 2002; Frazier, 1999). Most of the interviewed companies considered that intermediaries do not like their suppliers to engage in multi-channel distribution. Notwithstanding, many of these companies also think that intermediaries would not react adversely to a multi-channel move as long as their suppliers did not practise differential pricing or directly target their clients. An alternate strategy that some companies have been using to reduce channel conflict is the development of specialist brands and firms to deal with specific channels.

In smaller and fast growing markets, market size is less likely to provide sufficient resources to justify a multichannel strategy, and the ease with which companies can obtain resources from their environment (because the market is growing rapidly) implies that companies do not need to invest in multiple channels to obtain the resources they desire. This conforms with the observation made by Sa Vinhas and Anderson (2005) that market size enables the utilization of both integrated and non-integrated channels.

Improvements in competitive strength were observed to increase the usage of multiple channels. The more competitive companies tend to scrutinize the environment more acutely in search for new opportunities, and are more likely to respond proactively to environmental changes, such as market fragmentation and new technological developments. These companies are also more likely than others to constantly seek new ways of satisfying consumers with new products and delivery methods. In this context, they appear to be the most proactive in the development of multiple channel strategies.

Companies with a wider range of products make a more extensive use of multiple channels. A large number of product lines generates important scope economies, allowing companies to acquire the physical and managerial resources to implement a profitable multiple channel strategy. Company size, however, does not seem to be an important issue in going multi-channel. This is probably the result of some smaller companies making use of direct marketing (a less costly channel) to extend their geographical coverage.

\section{Conclusions and directions for future research}

This research has one or two limitations that affect the results and these should perhaps be recognized in future investigations. Firstly, although the financial institutions included in the research are drawn from all levels, it is not a randomly drawn sample. In addition, financial services may have special characteristics unique to the sector and hence the observed results may not transfer to other contexts. The study also considered a typology comprising three channels. In this context, it can be speculated that other typologies might have yielded different results. For the future, it is also important to conduct similar studies in other settings, in order to assess the extent to which these results can be generalized into other industries. Efforts should also be targeted at identifying other theoretical perspectives and factors with a potential bearing on the issue.

Future research should give particular attention to the development of channel typologies. Nowadays, there is a great variety of channels. The intermediary structure is quite diverse in many sectors. There is also a great variety of channels that can be owned by a company, particularly as a result of technological developments. In addition, manufacturers can resort to a different set of channels by developing arrangements that mix the characteristics of hierarchies and markets including, amongst others, alliances, joint ventures and long-term contracts. Clearly, there is a great need to develop typologies and measurements of the diversity of channels in use (Frazier, 1999). The construct validity of market target sophistication and channel conflict should also be further pursued, as the steps taken in this work were limited in this regard.

Future research should also address a related issue arising from the observation that, within a multiple channel structure, different channels can be utilized to perform different distribution functions. The allocation of functions among channels should be based on the characteristics of each channel, also being influenced by transaction costs, marketing and other factors.

Finally, more investigation is required on how to manage multiple channels. These channel structures may provide benefits that are too important to be neglected, but may also generate adversities that can put a company's survival at stake (see Moriarty and Moran, 1990). Consequently, research on this issue has potential for improving the efficiency and effectiveness that managers can obtain when developing these strategies.

\section{Appendix}

Description of measures and descriptive statistics and correlation coefficients are explained in Tables A1 and $\mathrm{A} 2$. 
Table A1

Description of measures

\begin{tabular}{|c|c|}
\hline Measure & Items \\
\hline Product sophistication & $\begin{array}{l}\text { Simple/complex } \\
\text { Unsophisticated/sophisticated } \\
\text { Risk-free/high risk } \\
\text { Short-term commitment/long-term commitment } \\
\text { Little money at stake/much money at stake } \\
\text { Small product variety/wide product variety }\end{array}$ \\
\hline Market target sophistication & $\begin{array}{l}\text { Our target customer has a higher income/education } \\
\text { Our target customer is more sophisticated on average }\end{array}$ \\
\hline Channel conflict & $\begin{array}{l}\text { The use of multiple channels creates conflict with intermediaries } \\
\text { Our sales through intermediaries would suffer a backlash if we used multiple channels }\end{array}$ \\
\hline Market maturity & $\begin{array}{l}\text { Stage of product life cycle (introduction/decline) } \\
\text { Prospects for future growth (low/high) (rev) }\end{array}$ \\
\hline Competitive strength & $\begin{array}{l}\text { Extent to which our strategy is monitored by competitors } \\
\text { Tendency to be ahead of competition (on products, channels,...) } \\
\text { Ability to gain market share }\end{array}$ \\
\hline Scope economies & Number of product lines marketed by the company (in intervals of four) \\
\hline Company size & Number of employees (logarithmized) \\
\hline
\end{tabular}

Table A2

Descriptive statistics and correlation coefficients

\begin{tabular}{|c|c|c|c|c|c|c|c|c|c|c|}
\hline & Mean & SD & Range & 1 & 2 & 3 & 4 & 5 & 6 & 7 \\
\hline 1. Product sophistication & 4.60 & 1.28 & 5.17 & - & & & & & & \\
\hline 2. Market target soph. & 4.22 & 1.54 & 6.00 & 0.08 & - & & & & & \\
\hline 3. Channel conflict & 3.39 & 1.86 & 6.00 & 0.23 & 0.34 & - & & & & \\
\hline 4. Market maturity & 3.53 & 1.31 & 5.00 & -0.39 & -0.28 & -0.12 & - & & & \\
\hline 5. Competitive strength & 4.06 & 1.15 & 4.67 & -0.24 & 0.24 & -0.03 & 0.04 & - & & \\
\hline 6. Scope economies & 2.74 & 1.61 & 5.00 & 0.18 & -0.39 & -0.17 & 0.09 & 0.04 & - & \\
\hline 7. Company size & 6.86 & 10.12 & 8.87 & -0.02 & -0.31 & -0.27 & 0.12 & 0.18 & 0.49 & - \\
\hline
\end{tabular}

\section{References}

Achrol, R.S., Reve, T., Stern, L.W., 1983. The environment of marketing channel dyads: a framework for comparative analysis. Journal of Marketing 47 (4), 55-67.

Aiken, L.S., West, S.G., 1991. Multiple regression: testing and interpreting interactions. Sage, London.

Alba, J., Lynch, J., Janiszewski, C., Lutz, R., Sawyer, A., 1997. Interactive home shopping: consumer, retailer, and manufacturer incentives to participate in electronic marketplaces. Journal of Marketing 61 (3), $38-53$.

Aldrich, H.E., 1979. Organisations and Environments. Prentice-Hall, Englewood Cliffs.

Andaleeb, S.S., 1995. Dependence relations and the moderating role of trust: implications for behavioral intentions in marketing channels. International Journal of Research in Marketing 12 (2), 157-172.

Anderson, E., Chu, W., Weitz, B., 1987. Industrial purchasing: an empirical exploration of the buyclass framework. Journal of Marketing 51 (3), 71-86.

Barney, J., 1991. The resource-based model of the firm: origins, implications, and prospects. Journal of Management 17 (1), 97-98.
Bello, D.C., Gilliland, D.I., 1997. The effect of output controls, process controls, and flexibility on export channel performance. Journal of Marketing 61 (1), 22-38.

Bengtsson, M., Kock, S., 2000. "Co-opetition" in business networks - to cooperate and compete simultaneously. Industrial Marketing Management 29 (5), 411-416.

Bradach, J.L., Eccles, R.G., 1989. Price, authority, and trust: from ideal types to plural forms. Annual Review of Sociology 15, 97-118.

Brandenburger, A.M., Nalebuff, B.J., 1996. Co-Opetition. Doubleday, New York.

Bucklin, L.P., Ramaswamy, V., Majumdar, S.K., 1996. Analysing channel structures of business markets via the structure-output paradigm. International Journal of Research in Marketing 13 (11), 73-87.

Burke, M.C., 1984. Strategic choice and marketing managers: an examination of business-level marketing objectives. Journal of Marketing Research 21 (4), 345-359.

Cespedes, F.V., 1988. Control vs. resources in channel design: distribution differences in one industry. Industrial Marketing Management 17 (3), 215-227.

Cespedes, F.V., Corey, R., 1990. Managing multiple channels. Business Horizons 33 (4), 67-77. 
Chandler, A.D., 1992. Organizational capabilities and the economic history of the industrial enterprise. Journal of Economic Perspectives 6 (3), 79-100.

Child, J., 1972. Organizational structure, environment and performance: the role of strategic choice. Sociology 6, 2-22.

Coelho, F., Easingwood, C., 2005. Determinants of multiple channel choice in financial services: an environmental uncertainty model. Journal of Services Marketing 19 (4), 199-211.

Cravens, D.W., 2000. Strategic Marketing, sixth ed. McGraw-Hill, Boston.

Degeratu, A.M., Rangaswamy, A., Wu, J., 2000. Consumer choice behavior in online and traditional supermarkets: the effects of brand name, price, and other search attributes. International Journal of Research in Marketing 17 (1), 55-78.

Diamantopoulos, A., Winklhofer, H.M., 2001. Index construction with formative indicators: an alternative to scale development. Journal of Marketing Research 38 (2), 269-277.

Dozoretz, J., Matanovich, T., 2002. The deadly dynamics of price competition. Marketing Research 14, 26-31.

Dutta, S., Bergen, M., Heide, J.B., John, G., 1995. Understanding dual distribution: the case of reps and house accounts. Journal of Law, Economics, \& Organisation 11 (1), 189-205.

Dwyer, R., Welsh, M.A., 1985. Environmental relationships of the internal political economy of marketing channels. Journal of Marketing Research 22 (4), 397-414.

Easingwood, C., Coelho, F., 2003. Single versus multiple channel strategies: typologies and drivers. Service Industries Journal 23 (2), 31-46.

Easingwood, C., Storey, C., 1996. The value of multi-channel distribution systems in the financial services sector. Service Industries Journal 16 (2), 223-241.

Farris, P., Oliver, J., Kluyver, C., 1989. The relationship between distribution and market share. Marketing Science 8 (2), 107-127.

Filloto, U., Tanzi, P.M., Saita, F., 1997. Customer needs and front-office technology adoption. International Journal of Bank Marketing 15 (1), 13-21.

Frazier, G.L., 1999. Organizing and managing channels of distribution. Journal of the Academy of Marketing Science 27 (2), 226-240.

Frazier, G.L., Lassar, W.M., 1996. Determinants of distribution intensity. Journal of Marketing 60 (4), 39-51.

Gaski, J.F., Nevin, J.R., 1985. The differential effects of exercised and unexercised power sources in a marketing channel. Journal of Marketing Research 22 (2), 130-142.

Gassenheimer, J.B., Hunter, G.L., Siguaw, J.A., 2006. An evolving theory of hybrid distribution: taming a hostile supply network. Industrial Marketing Management, in press, doi:10.1016/j.indmarman.2006.02.007.

Gatignon, H., Robertson, T.S., 1991. Innovative decision processes. In: Robertson, T.S., Kassarjian, H.H. (Eds.), Handbook of Consumer Behavior. Prentice-Hall, Englewood Cliffs.

Hair, J., Bush, R.P., Ortinau, D.J., 2002. Marketing Research: Within a Changing Information Environment, second ed. McGraw-Hill, London.

Hamel, G., Prahalad, C.K., 1995. Strategic intent. In: Mintzberg, H., Quinn, J.B., Ghoshal, S. (Eds.), The Strategy Process, European ed., Prentice-Hall, London, pp. 34-40.
Hibbard, J.D., Kumar, N., Stern, L.W., 2001. Examining the impact of destructive acts in marketing channel relationships. Journal of Marketing Research 38 (1), 45-61.

Howell, R.D., 1987. Covariance structure and measurement issues: a note on "Interrelations among a channel entity's power sources". Journal of Marketing Research 24 (1), 119-126.

Im, S., Bayus, B.L., Mason, C.H., 2003. An empirical study of innate consumer innovativeness, personal characteristics, and new-product adoption behaviour. Journal of the Academy of Marketing Science 31 (1), 61-73.

Jap, S.D., 2001. Perspectives on joint competitive advantages in buyerseller relationships. International Journal of Research in Marketing 18 (1-2), 19-35.

Klein, S., Frazier, G.L., Roth, V.J., 1990. A transaction cost analysis model of channel integration in international markets. Journal of Marketing Research 27 (2), 196-208.

Lassar, W.M., Kerr, J.L., 1996. Strategy and control in supplierdistributor relationships: an agency perspective. Strategic Management Journal 17 (8), 613-632.

Majumdar, S.K., Ramaswamy, V., 1994. Explaining downstream integration. Managerial and Decision Economics 15 (2), 119-129.

Majumdar, S.K., Ramaswamy, V., 1995. Going direct to market: the influence of exchange conditions. Strategic Management Journal 16 (5), 353-372.

Moriarty, R., Moran, U., 1990. Managing hybrid marketing systems. Harvard Business Review 68 (6), 146-155.

Netemeyer, R.G., Pulig, C., Bearden, W.O., 2001. Some Observations on Self-Report Paper and Pencil Measures. Society for Marketing Advances Distinguished Scholar Series. Elsevier, New York.

Pfeffer, J., Salancik, G.R., 1978. The External Control of Organisations: A Resource Dependence Perspective. Harper and Row, London.

Rangan, V.K., Menezes, M.A.J., Maier, E.P., 1992. Channel selection for new industrial products: a framework, method, and application. Journal of Marketing 56 (3), 69-82.

Rangan, V.K., Corey, E.R., Cespedes, F., 1993. Transaction cost theory: inferences from field clinical research on downstream vertical integration. Organisation Science 4 (3), 454-477.

Rogers, E.M., 1995. Diffusion of Innovations. Free Press, New York.

Sa Vinhas, A., Anderson, E., 2005. How potential conflict drives channel structure: concurrent (direct and indirect) channels. Journal of Marketing Research 42 (4), 507-515.

Schiffman, L.G., Kanuk, L.L., 1991. Consumer Behaviour, fourth ed. Prentice-Hall, London.

Stern, L.W., Studirvant, F.D., Getz, G.A., 1993. Accomplishing marketing channel change: paths and pitfalls. European Management Journal 11 (1), 1-8.

Stern, L.W., El-Ansary, A.I., Coughlan, A.T., 1996. Marketing Channels, fifth ed. Prentice-Hall, London.

The Economist, 2000. Shopping around the Web. Internet Survey, February 26th-March 3rd, p. 16.

Webb, K.L., Hogan, J.E., 2002. Hybrid channel conflict: causes and effects on channel performance. Journal of Business and Industrial Marketing 17 (5), 338-356.

Wheelwright, S.C., Clark, K.B., 1992. Revolutionizing Product Development. The Free Press, New York.

Zettelmeyer, F., 2000. Expanding to the internet: pricing and communications strategies when firms compete on multiple channels. Journal of Marketing Research 37 (3), 292-308. 